\title{
Effect of Adding Magnesium Oxide Nanoparticles on the Antimicrobial Activity of a Denture Soft Liner
}

\author{
Hoshang Kh. Abdel-Rahman, Salem A. Salem AL-Sammaraie \\ Department of Prosthodontic, College of Dentistry, Hawler Medical University, Erbil, Kurdistan Region, Iraq
}

\section{*Corresponding author: Hoshang Kh. Abdel-Rahman, Department of Prosthodontic, College of Dentistry, Hawler Medical University, Erbil, Kurdistan Region, Iraq. \\ E-mail: hoshang. \\ abdelrahman@hmu.edu.krd}

Received: 29 April 2020

Accepted: 12 July 2020

Published: 30 December 2020

DOI

10.25156/pti.v10n2y2020.pp132-137

\section{A B S T R A C T}

Microbial growth and colonization are one of the disadvantages after the long-term use of denture soft liners. This study was aimed to evaluate the effect of the addition of magnesium oxide nanoparticles (MgONPs) on the antimicrobial activity of a denture soft liner. A total of 84 samples were prepared from a soft denture liner and divided into two groups, control group and test group to which $3 \%$ by weight of MgONPs were added, antimicrobial tests for Candida albicans, Staphylococcus aureus, and a mixture of the biofilm of both microorganisms were done, cell density count and adherence assay test was recorded before and after 6 months storage in distilled water. The results showed that the modified group performed a better antimicrobial activity compared to the control group, the addition of $3 \%$ of the nanofiller showed a significant reduction in the mean value of growth of both $C$. albicans, $S$. aureus, and the biofilm mixture $(P<0.05)$ before and after the storage period. In conclusion, the addition of $3 \%$ by weight of MgONPs to the denture soft liner significantly suppressed the growth of C. albicans, S. aureus up to 6 months.

Keywords: Soft liner; Nanoparticle; Candida albicans; Staphylococcus aureus; Biofilm; Soft liner; Nanoparticles

\section{INTRODUCTION}

The denture base is the part of the denture that rests on the foundation tissues and to which teeth are attached (GPT-9, 2017). Nowadays, the acrylic resin material is the most commonly used polymer for denture base because it meets most of the requirements for clinically acceptable denture base material (Zarb et al., 2013). Dentures may gradually lose their stability and retention due to changes in the denture supporting tissues and/or occlusal disharmony, which subsequently contribute to the host abuse (Craig et al., 2004). Hence, the objective of relining is to re-surface the impression surface of the denture and provide more accurate adaptation and fitness to the underlying supporting tissues (Zarb et al., 2013). The denture lining materials classified as hard and soft (Mitchel and Mitchel, 2005). They have been used to provide the comfort of the denture wearing experience, especially for those patients having sharp knifeedged residual ridges and complaining of pain and soreness on denture wearing, rendering them unable to bear the functional and masticatory stresses (Raval et al., 2017).

The denture soft liners usually have a porous surface (Saravanan et al., 2015); these porosities make these materials to act as excellent reservoirs microbial colonization (Valentini et al., 2017).
The oral cavity contains a variety of microbial species such as bacteria, viruses, and fungi, which are capable to develop dental plaque (Avila et al., 2009). The antimicrobial property of denture soft liners is usually provided with the addition of antimicrobial agents; however, this modification often causes a variety of changes in the physical, chemical, and mechanical properties of the materials that limiting its use (Urban et al., 2015). Many additives were incorporated to the soft denture liners as antimicrobial agents $(\mathrm{Nam}$, 2011; Zayed et al., 2014; Abdullah, 2015; Ahmed and Ali, 2018). Magnesium oxide nanoparticles (MgONPs) have been documented to have antimicrobial properties (Robinson et al., 2010), unlike many of the other metal oxides formulas, Magnesium has a very little inherent risk of cellular toxicity (Huang et al., 2005).

The current study is aimed to test and evaluate the antimicrobial properties of a silicone-based denture soft liner modified with the addition of $3 \%$ of MgONPs.

\section{MATERIALS AND METHODS}

Mollosil, which is an a-silicone-based chemical cure denture liner, was used, it is consists of two pastes, base, and catalyst and was mixed together in an equal ratio (1:1 base:catalyst) according to the manufacturer instruction. 
The used $\mathrm{MgONP}$ had a purity of $99+\%$ and an average diameter of $20 \mathrm{~nm}$, as shown in Figure 1.

A digital weight scale was used for measuring the weight of base and catalyst, then 3\% of MgONPs by weight was added to the material. The selection of this concentration was done according to a pilot study; different concentrations of $\mathrm{MgONPs}(2 \%, 3 \%, 4 \%, 5 \%$, and $6 \%)$ by weight were added to the soft liner to determine which concentration gives the best antimicrobial result. Accordingly, the results indicated that the modified group with $3 \% \mathrm{MgONPs}$ provided the best inhibitory effect on Candida albicans and Staphylococcus aureus growth compared to the control group and the other modified groups, as seen in Tables 1 and 2, respectively.

Before the preparation of the samples, $\mathrm{MgONPs}$ were sterilized in a hot air oven at $200^{\circ} \mathrm{C}$ for $1 \mathrm{~h}$, the reason for using this method of sterilization is due to the fact that the other methods for sterilization or disinfection for $\mathrm{MgONPs}$ are not allowed because of the nature of $\mathrm{MgONPs}$ which is hygroscopic so that autoclaving process is not considered as an ideal method for sterilization because of the possibility of the phase change of the $\mathrm{MgONPs}$ due to the presence of the water in the steam of the autoclave, this, in turn, may affect the accuracy of the results against microorganisms. Moreover, $\mathrm{MgONPs}$ have the tendency to absorbs ultraviolet (UV) light and interacts with oxygen molecules (Yanagisawa and Huzimura, 1981; Wetteland et al., 2018).
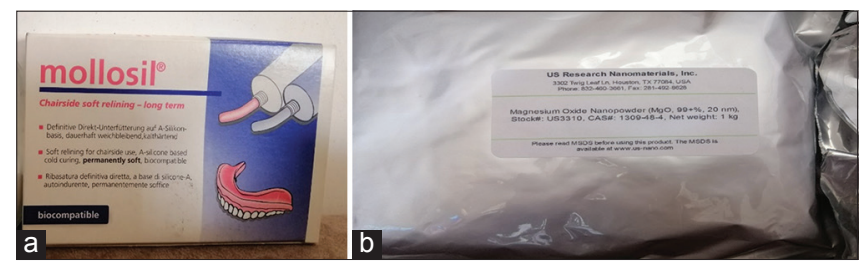

Figure 1: a. Silicone soft liner test material, b. Magnesium oxide nanoparticles package
The MgONPs were added in small traces to the base part of the soft liner and mixed together for $1 \mathrm{~min}$ in a circular motion (120 cycles/min), then mixed for another 3 min using a sterilized lentulo spiral (file) attached to the slow speed handpiece, after that the catalyst part was added to them and mixed for $30 \mathrm{~s}$, according to manufacturer instructions [Table 3].

All the samples were prepared at room temperature. Sample numbers and grouping are shown in Table 4.

The specimens were prepared using a square-shaped mold (60 $\mathrm{mm}$ length and $1.5 \mathrm{~mm}$ thickness), as seen in Figure 2.

Standard American type culture collection ATCC (10231) approved that $C$. albicans was collected from a reference laboratory. Sabouraud Dextrose Agar medium was prepared; the medium was placed in an incubator for $24 \mathrm{~h}(24 \mathrm{~h})$ at $37^{\circ} \mathrm{C}$. Then, C. albicans suspension was standardized by diluting it with sterile phosphate buffer saline (PBS) so that the concentration of the yeast culture kept at $10^{7} \mathrm{CFU} / \mathrm{ml}$. Later, one colony of C. albicans was inoculated in $5 \mathrm{~mL}$ of Sabouraud dextrose broth at $37^{\circ} \mathrm{C}$ for $24 \mathrm{~h}$.

The microbiological test started immediately after C. albicans was prepared by placing the sample in an autoclaved test cups. The test cups were incubated for $3 \mathrm{~h}$ at $37^{\circ} \mathrm{C}$ under aerobic conditions. Later, the samples were removed and washed with sterile (PBS), then, each sample was placed in another new test cups filled with $15 \mathrm{~mL}$ fresh brain heart infusion (BHI) and yeast nitrogen base (YNB) media. Finally, they were placed in the incubator for $24 \mathrm{~h}$ at $37^{\circ} \mathrm{C}$ under aerobic conditions allowing the growth and formation of the biofilm on the test samples.

For the anti-Candida test, a total of 28 samples were prepared, 14 samples were stored in an autoclaved test cups containing

Table 1: Result of cell density counting for $C$. albicans (pilot study)

\begin{tabular}{lcccccc} 
C. albicans & Control 0\%MgONPs & 2\% MgONPs & 3\% MgONPs & 4\% MgONPs & 5\% MgONPs & 6\% MgONPs \\
\hline Sample 1 & 0.088 & 0.073 & 0.057 & 0.062 & 0.068 & 0.072 \\
Sample 2 & 0.086 & 0.075 & 0.058 & 0.064 & 0.070 & 0.071 \\
Sample 3 & 0.090 & 0.075 & 0.057 & 0.064 & 0.0067 & 0.073 \\
Average & 0.088 & 0.0743 & 0.0573 & 0.0633 & 0.0683 & 0.0720 \\
\hline
\end{tabular}

MgONPs: Magnesium oxide nanoparticles, C. albicans: Candida albicans

Table 2: Result of cell density counting for S. aureus (pilot study)

\begin{tabular}{lcccccc} 
S. aureus & Control 0\%MgONPs & 2\% MgONPs & 3\% MgONPs & 4\% MgONPs & 5\% MgONPs & 6\% MgONPs \\
\hline Sample 1 & 1.101 & 0.071 & 0.046 & 0.046 & 0.0480 & 0.0490 \\
Sample 2 & 1.105 & 0.068 & 0.044 & 0.043 & 0.0470 & 0.0520 \\
Sample 3 & 1.102 & 0.068 & 0.044 & 0.044 & 0.0480 & 0.0500 \\
Average & 1.102 & 0.069 & 0.0443 & 0.0446 & 0.0476 & 0.0530 \\
\hline
\end{tabular}

MgONPs: Magnesium oxide nanoparticles, S. aureus: Staphylococcus aureus 
Table 3: Sample constituent for antimicrobial activity test

\begin{tabular}{lcccc}
\hline Sample label & $\begin{array}{c}\text { Base } \\
\text { part }(\mathrm{g})\end{array}$ & $\begin{array}{c}\text { Catalyst } \\
\text { part }(\mathrm{g})\end{array}$ & $\begin{array}{c}\text { MgONPs } \\
(\mathrm{g})\end{array}$ & $\begin{array}{c}\text { Total } \\
(\mathrm{g})\end{array}$ \\
\hline Control (0\% MgONPs) & 0.50 & 0.50 & 0 & 1 \\
(3\% MgONPs) & 0.485 & 0.50 & 0.015 & 1 \\
\hline
\end{tabular}

MgONPs: Magnesium oxide nanoparticles

Table 4: Sample numbers and grouping

\begin{tabular}{lcccc} 
& $\begin{array}{c}\text { Control group } \\
\text { (number) } \\
\text { storage after storage }\end{array}$ & $\begin{array}{c}\text { Modified (test) group } \\
\text { (number) Before } \\
\text { storage after storage }\end{array}$ \\
\hline C. albicans & 7 & 7 & 7 & 7 \\
S. aureus & 7 & 7 & 7 & 7 \\
$\begin{array}{l}\text { Mixed C. albicans } \\
\text { and S. aureus }\end{array}$ & 7 & 7 & 7 & 7 \\
\hline
\end{tabular}

C. albicans: Candida albicans, S. aureus: Staphylococcus aureus

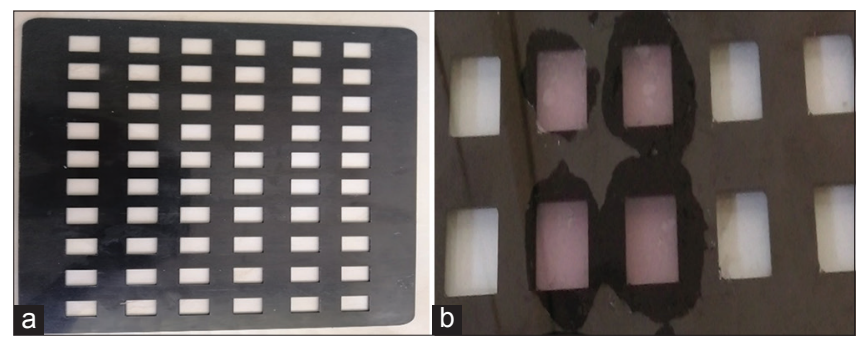

Figure 2: a Microbiology sample mold, b. Fabricated samples

distilled water (D.W) at constant temperature $37^{\circ} \mathrm{C}$ for 6 months, the remaining 14 samples were immediately used for determining the anti-Candida effect after $24 \mathrm{~h}$.

Regarding the bacterial culture process, a standard ATCC 25923 approved that $S$. aureus was collected from a reference laboratory. The bacteria were grown on blood agar, then one colony of the bacteria strain was inoculated in $5 \mathrm{~mL}$ of $30 \% \mathrm{BHI}$ with $70 \% \mathrm{YNB}$ for $24 \mathrm{~h}$ at $37^{\circ} \mathrm{C}$.

The concentration of the bacteria was kept to $10^{7} \mathrm{CFU} / \mathrm{mL}$ in $30 \% \mathrm{BHI}$ and $70 \% \mathrm{YNB}$ Broth. After that, the sample pattern, size, and numbers were done similar to the previously mentioned method for $C$. albicans.

Analysis of antimicrobial activity by cell density count was done after completion of the incubation process, each sample was removed gently using sterilized tweezer from the cup, then rinsed by dipping in the sterile cup containing $50 \mathrm{ml}$ of PBS solution for $75 \mathrm{~s}$ for 3 times. Then, each sample was suspended again in $2 \mathrm{ml}$ of PBS solution and shacked at maximum speed by vortex device, this to ensure that cells were completely released from the surface of the specimen, then, the specimen was removed from the solution.

The solution was used for the cell density counting, while the specimens were used for evaluation of the adherence assay test. The obtained solution was sonicated for 3 min to destroy the microbial aggregations. Later, the suspended biofilms were placed inside a sterilized 96 well plates and inserted into the spectrophotometric device at the wavelength 490 to measure the rate of absorbance. To determine whether a biofilm was developed on the surface of the soft liner samples or not, the specimens were gently rinsed by dipping it into the sterile PBS solution for approximately $60 \mathrm{~s}$ for 3 times to remove the unattached pathogen cells to the sample surfaces. Then, for fixation of the attached cells, specimens were treated with 100\% ethanol for $3 \mathrm{~s}$ and left dry in sterile plates at room temperature. Finally, the samples were stained using sterilized, Methylene blue stain (0.1\%) for $1 \mathrm{~min}$.

Finally, the samples were evaluated under an optical light/ dissecting microscope to determine whether the biofilm was developed on the surface of the soft liner samples.

\section{RESULTS}

The anti-Candida test of the soft liner by optical density method showed that the modified group performed a better anti-Candida growth compared to the control group and caused a statistically significant reduction in the mean value of the Candida growth, as seen in Table 5 .

After 6-month conditioning (incubation) of both groups in D.W, there was a reduction in the anti-Candida activity compared to the value before the conditioning procedure. For the control group, there was a significant increase in the mean value of $C$. albicans growth after 6-month storage in D.W. However, the test group again performed better than the control group and exhibited a greater anti-Candida growth resistance, but the difference in $C$. albicans growth was significantly increased after 6-month storage in D.W.

Regarding the antibacterial growth, the results showed that the addition of $3 \% \mathrm{MgONPs}$ to the soft liner significantly decreased the growth of the $S$. aureus before conditioning the samples in D.W. Table 6. Storing the soft liner samples in D.W for 6-month decreased the antibacterial effect, as there was an increase of bacterial growth for both groups compared to their correspondent before storage in D.W and this difference was statistically significant for both groups.

When cell density counting was done before storage in D.W for the biofilm (mixed C. albicans and S. aureus), the results showed that the growth of this combination was more on the controlled group compared to the test group [Table 7], the results showed that the difference was statistically highly significant $(P>0.001)$. 
Table 5: Cell density counting for $\boldsymbol{C}$. albicans

\begin{tabular}{lcc}
\hline & $\begin{array}{c}\text { Before storage } \\
\text { in D.W } \\
n=7 \text { Mean+SD }\end{array}$ & $\begin{array}{c}\text { After 6-month storage } \\
\text { in D.W } \\
n=7 \text { Mean }+ \text { SD }\end{array}$ \\
\hline Control group $n=14$ & $\begin{array}{c}0.08714 \\
(0.006067)^{\mathrm{A}, \mathrm{a}}\end{array}$ & $0.10243(0.001272)^{\mathrm{B}, \mathrm{b}}$ \\
Test group $n=14$ & 0.05629 & $0.06943(0.001902)^{\mathrm{B}, \mathrm{C}}$ \\
& $(0.003592)^{\mathrm{A}, \mathrm{b}}$ & \\
$P$ value & 0.000 & 0.000 \\
\hline
\end{tabular}

Groups with the same uppercase superscript letters for each row and lowercase superscript letters for each column are not significantly different at the $P<0.05$ level. C. albicans: Candida albicans, D.W: Distilled water

Table 6: Cell density counting for $S$. aureus

\begin{tabular}{lcc} 
& $\begin{array}{c}\text { Before storage } \\
\text { in D.W } \\
n=7 \text { Mean+SD }\end{array}$ & $\begin{array}{c}\text { After 6-month storage } \\
\text { in D.W } \\
n=7 \text { Mean+SD }\end{array}$ \\
\hline Control group $n=14$ & $\begin{array}{c}0.10386 \\
(0.004220)^{\mathrm{A}, \mathrm{a}}\end{array}$ & $0.12087(0.001773)^{\mathrm{B}, \mathrm{b}}$ \\
Test group $n=14$ & $\begin{array}{c}0.04657 \\
(0.001813)^{\mathrm{A}, \mathrm{b}}\end{array}$ & $0.05357(0.001988)^{\mathrm{B}, \mathrm{C}}$ \\
& 0.000 & 0.000 \\
\hline value &
\end{tabular}

Groups with the same uppercase superscript letters for each row and lowercase superscript letters for each column are not significantly different at the $P<0.05$ level. S. aureus: Staphylococcus aureus, D.W: Distilled water

Table 7: Cell density counting for $\boldsymbol{C}$. albicans mixed with S. aureus

\begin{tabular}{lcc}
\hline & $\begin{array}{c}\text { Before storage in } \\
\text { D.W } \\
n=7 \text { Mean+SD }\end{array}$ & $\begin{array}{c}\text { After 6-month } \\
\text { storage in D.W } \\
n=7 \text { Mean+SD }\end{array}$ \\
\hline Control group $n=14$ & $0.10886(0.0010)^{\mathrm{A}, \mathrm{a}}$ & $0.12714(0.0016)^{\mathrm{B}, \mathrm{b}}$ \\
Test group $n=4$ & $0.04986(0.0020)^{\mathrm{A}, \mathrm{b}}$ & $0.05814(0.0030)^{\mathrm{B}, \mathrm{c}}$ \\
$P$ value & 0.000 & 0.000 \\
\hline
\end{tabular}

Groups with the same uppercase superscript letters for each row and lowercase superscript letters for each column are not significantly different at the $P<0.05$ level, $C$. albicans: Candida albicans, $S$. aureus: Staphylococcus aureus, D.W: Distilled water

After 6-month of storage in D.W, the cell density counting for the control and test group was drastically increased, but the results showed the exact pattern as that before storage in D.W and again the test group showed a better resistance than the control group, the difference was highly significant $P \leq 0.001$.

For adherence assay test, the result showed that the antimicrobial effect on the surface of the soft denture liner modified with 3\% of MgONPs was more effective and performed better resistance for $C$. albicans growth (in the term of number of colonies) than that of the controlled group before storage of the samples in the D.W. The same formula was detected for the $S$. aurens group and also for the mixed group (C. albicans with $S$. aureus).

After 6-month storage in D.W, the samples matching showed the same pattern as was seen as that before storage, indicating that the additive ( $3 \% \mathrm{MgONPs}$ ) showed the antimicrobial activity even after storage in D.W but with a lesser effect compared to that before storage.

\section{DISCUSSION}

The results of this study were similar to Kanathila et al. (2011) when they studied the effectiveness of different concentrations $(1 \%, 3 \%, 5 \%$, and $7 \%)$ of magnesium oxide combined with tissue conditioners, it was found that the anti-candidal activity increased as the concentration of the $\mathrm{MgO}$ increased, this finding was also observed by Nguyen et al. (2018) when they found that minimum fungicidal concentration was at higher doses for three strains of Candida species, also agreed with other previous studies (Baygar et al., 2018; Abdulwahhab and Jassim, 2018; Chinchollkar et al., 2019) when they found that there was an inhibitory effect of the added antifungal fillers to the denture soft liners, this may be due to the alteration of the lipid bilayer membrane, which may change the membrane functions, which in turn may alter the fungal cells permeability and affect the membranes ability to osmoregulate the cells adequately or to exclude toxic materials and some low-molecular-weight components may penetrate and cause cellular damage (Naeini et al., 2014).

Furthermore, the result of this study was agreed with Ahmed and Ali, 2018; Issa and Abdul-Fattah, 2015; Singh et al., 2018; Kreve et al., 2019, when they studied the effect of incorporation of nanoparticles to the denture soft lining materials and also agreed with other studies (Meran and Salem, 2020) when $3 \%$ of MgONPs was incorporated to a silicone maxillofacial silicone and found a significant inhibitory effect of these fillers against $C$. albicans.

It was reported that nanoparticles cause C. yeast cell death by production of intracellular reactive oxygen species (ROS), causing oxidation of the Coenzyme A and peroxidation of lipids, which decrease respiratory activity and thus cell death (Haghighi et al., 2013). Another explanation might be due to the cell membrane tearing of fungi caused by $\mathrm{MgONP}_{\mathrm{S}}$, which disturb its integrity, loss of intracellular substances and suppression of the natural budding process through defecting cell cycle at pre-mitotic phase (Kamikawa et al., 2014) or inhibited the metabolic activity of C. albicans (Garner et al., 2015).

Finally, this increase in the antifungal activity might be due to the fact that the soft liner used in the present study is a chairside auto polymerized type, so the temperature rise during the polymerization process of the soft liners is minimum thus does not cause any deleterious effect on the antifungal efficacy of the added fillers (Chinchollkar et al., 2019).

On the opposite side, the obtained results disagree with Abdullah, 2015, when she found a non-significant antifungal activity in a denture soft liner incorporated with different concentrations of $\mathrm{ZnO}$ nanoparticles, this 
may be due to differences in the chemical composition of the polymer used, and a different type of nanoparticles formula. However, another reason may be she used high concentrations of the ZnONPs, which leads to agglomeration (Chladek et al., 2011), which may create porosities inside the material facilitating the colonization of the fungi.

It was found that MgONPs have a good bactericidal activity toward both Gram-negative and Gram-positive bacteria, though they were more efficient against gram-positive bacteria (Avanzato et al., 2009).

The result from this study is similar to other studies (Baygar et al., 2018; Singh et al., 2018; Stencel et al., 2018) when they found that the addition of the antibacterial agents to soft liners significantly decrease the bacterial activity. This may be due to the fact that the addition of MgONPs to a bacterial growth media resulted in a rapid increase in $\mathrm{pH}$ of the medium (Robinson and Conzemius, 2012); the other explanation may be the induction of oxidative stress due to the generation of ROS, such as superoxide anion $\left(\mathrm{O}^{2-}\right)$ (Yamamoto et al., 2010). This may cause the degradation of the membrane structure of the cell. Moreover, the release of ions from the surface of MgONPs may lead to bacterial death due to binding to cell membrane (Kim et al., 2007; Emamifar et al., 2011). Furthermore, the increase of the surface area of $\mathrm{MgO}$ particles may lead to an increase of the $\mathrm{O}^{2-}$ concentration in solution and thus results in more effective destruction of the cell wall of the bacteria (Yamamoto et al., 2000).

According to Huang et al. (2005), the antibacterial activity was increased when the $\mathrm{MgO}$ particle size decreased, this may be another reason for such a significant reduction in the microbial activity since the used particle size was the smallest size $(20 \mathrm{~nm})$.

In contrast, the present study disagreed with Kreve et al., 2019, when studied the influence of incorporation of different concentrations of $\mathrm{AgVO} 3$ nanoparticle on a soft denture liner, they found that none of the concentrations was effective against $S$. aureus; the reason for this dissimilarity may be due to the fact the chemical composition of the soft denture liner which was acrylic rather than silicone material; also the used nanoparticle was differ from the one used in this study.

Antibacterial activity of MgONPs against $S$. aureus was higher at the same concentrations than for C. albicans, this may be due to the nature of the Candida, which is unlike bacteria because Candida are eukaryotic cells and have both a fungal cell wall and a cell membrane (Nguyen et al., 2018; Meran and Salem, 2020; Lipke and Ovalle, 1998).
When the results of this study for the mixture of biofilm of $C$. albicans and $S$. aureus were tested, it was clear that the microbial growth of the biofilm before and after 6-month of storage in D.W was more dominant on the control group than the modified group, and this finding was in agreement with other studies (Chinchollkar et al., 2019; Kreve et al., 2019) when incorporated nanoparticle to the soft denture liners, and agreed with results of Meran and Salem, 2020 when studied the effect of 3\% of MgONPs on silicone maxillofacial material, also agreed with Nam, 2011, when found that the addition of silver nanoparticles reduce the biofilm activity on the tissue conditioning material, the explanation for this microbial adherence and growth on the surface of the soft denture liner may be due to the character of the surface of the silicone materials which have a high hydrophobic surface, rendering them more susceptible to interact with the macromolecules, so it will adsorb significant protein from the surrounding biologic environment (Chen et al., 2004), this protein will accelerate the attachment of the microorganisms and form a biofilm layer on the surface (Dominic et al., 2007).

\section{CONCLUSION}

The addition of $3 \%$ of MgONPs to the denture soft liner significantly improved the antimicrobial activity against $C$. albicans, $S$. aurens, and a biofilm mixture of both microorganisms up to 6 months.

\section{REFERENCES}

Abdullah, Z. K. 2015. The Effect of Thermocycling on Some Properties of Modified Silicone Soft Denture Liner. M.Sc. Thesis. Hawler Medical University, Iraq.

Abdulwahhab, A. R. and R. K. Jassim. 2018. The effect of aloe vera extract on adherence of Candida albicans and other properties of heat cure denture soft lining material. Int. J. Med. Res. Health Sci. 7(3): 94-103.

Ahmed, A. Q. and M. M. Ali. 2018. The influence of titanium dioxide nanoparticles incorporation into soft denture lining material on Candida albicans adherence and some mechanical and physical properties. J. Pure Appl. Microbiol. 12(2): 783-791.

Avanzato, C. T., J. M. Follieri and I. A. Banerjee. 2009. Biomimetic synthesis and antibacterial characteristics of magnesium oxidegermanium dioxide nanocomposite powders. J. Compos. Mater. 43: 897-910.

Avila, M., D. M. Ojcius and O. Yilmaz. 2009. The oral microbiota: Living with a permanent guest. DNA. Cell. Biol. 28(8): 405-411.

Baygar, T., A. Ugur, N. Sarac, U. Balci and G. Ergun. 2018. Functional denture soft liner with antimicrobial and antibiofilm properties. J. Dent. Sci. 13: 213-219.

Chen, Y., L. Huang, C. Chan, C. Su, S. Chang, Y. Y. Chang, M. L. Chen, C. C. Hung, W. J. Chen, F. Y. Lin and Y. T. Lee. 2004. SARS in hospital emergency room. Emerg. Infect. Dis. 10: 782-788.

Chinchollkar, S., J. Sridevi, N. Kalavathy, S. Singh, A. Kapoor and S. Saumya. 2019. Comparative evaluation of two antifungal 
agents incorporated in auto polymerising denture base resin, heat polymerising denture base resin and permanent silicone soft liner-an in vitro study. J. Clin. Diagn. Res. 13(1): 49-54.

Chladek, G., A. Mertas, I. Barszczewska-Rybarek, T. Nalewajek, J. Żmudzki, W. Król and J. Łukaszczyk. 2011. Antifungal activity of denture soft lining material modified by silver nanoparticles a pilot study. Int. J. Mol. Sci. 12: 4735-4744.

Craig, R. G., J. M. Powers and J. C. Wataha. 2004. Dental Materials: Properties and Manipulation. $8^{\text {th }}$ ed. Mosby, Maryland Heights, Missouri.

Dominic, R., S. Shenoy and S. Baliga. 2007. Candida biofilms in medical devices: Evolving trends. Kathmandu Univ. Med. J. 10(3): 431-436.

Emamifar, A., M. Kadivar, M. Shahedi and S. Solaimanianzad. 2011. Effect of nanocomposite packaging containing $\mathrm{Ag}$ and $\mathrm{ZnO}$ on inactivation of Lactobacillus plantarum in orange juice. Food Control. 22: 408-413.

Garner, S. J., A. H. Nobbs, L. M. McNally and M. E. Barbour. 2015. An antifungal coating for dental silicones composed of chlorhexidine nanoparticles. J. Dent. 43: 362-372.

Haghighi, F., S. R. Mohammadi, P. Mohammadi, S. Hosseinkhani and R. Shipour. 2013. Antifungal activity of $\mathrm{TiO}_{2}$ nanoparticles and EDTA on Candida albicans biofilms. Infect. Epidemiol. Microbiol. 1(1): 33-38.

Huang, L., D. Q. Li, Y. J. Lin, M. Wei, D. G. Evans and X. Duan. 2005. Controllable preparation of nano-MgO and investigation of its bactericidal properties. J. Inorg. Biochem. 99: 986-993.

Issa, M. I. and N. Abdul-Fattah. 2015. Evaluating the effect of silver nanoparticles incorporation on antifungal activity and some properties of soft denture lining material. J. Baghdad Coll. Dent. 27(2): 17-23.

Kamikawa, Y., D. Hirabayashi, T. Nagayama, J. Fujisaki, T. Hamada, R. Sakamoto, Y. Kamikawa and K. Sugihara. 2014. In vitro antifungal activity against oral Candida species using a denture base coated with silver nanoparticles. J. Nanomater. 2014: 780410

Kanathila, H., A. M. Bhat and P. D. Krishna. 2011. The effectiveness of magnesium oxide combined with tissue conditioners in inhibiting the growth of Candida albicans: An in vitro study. Indian J. Med. Res. 22(4): 613.

Kim, Y. M., E. Kuk, K. N. Yu, J. H. Kim, S. J. Park and H. J. Lee. 2007. Antimicrobial effects of silver nanoparticles. Nanomedicine. 3: 95-101.

Kreve, S., V. c. Oliveira, L. Bachmann, O. L. Alves and A. C. Dos Reis. 2019. Influence of $\mathrm{AgVO}_{3}$ incorporation on antimicrobial properties, hardness, roughness and adhesion of a soft denture liner. Sci. Rep. 9: 1-9.

Lipke, P. N. and R. Ovalle. 1998. Cell wall architecture in yeast: New structure and new challenges. J. Bacteriol. 180: 3735-3740.

Meran, Z. and A. S. Salem. 2020. The effect of magnesium oxide nanoparticles impregnated into silicone facial prostheses against Candida albicans and Staphylococcus epidermidis. Crescent J. Med. Biol. Sci. 6(4): 466-472.

Mitchel, D. A. and L. Mitchel. 2005. Oxford Handbook of Clinical Dentistry. $4^{\text {th }}$ ed. Oxford University Press, New York.

Naeini, A. N. J. Naderi. and H. Shokri. 2014 Analysis and in vitro antiCandida antifungalactivity of Cuminum cyminum and Salvadora persica herbs extracts against pathogenic Candida strains. J. Mycol. Med. 24: 13-18.
Nam, K. Y. 2011. In vitro antimicrobial effect of the tissue conditioner containing silver nanoparticles. J. Adv. Prosthodont. 3(1): 20-24.

Nguyen, N. T. N., N. Grelling, C. L. Wetteland, R. Rosario and H. H. Liu. 2018. Antimicrobial activities and mechanisms of magnesium oxide nanoparticles $(\mathrm{nMgO})$ against pathogenic bacteria, yeasts, and biofilms. Sci. Rep. 8: 16260.

Raval, H. J., N. Mahajan, Y. G. Naveen and R. Sethuraman. 2017. A three month comparative evaluation of the effect of different surface treatment agents on the surface integrity and softness of acrylic based soft liner: An in vivo study. J. Clin. Diagn. Res. 11(9): 88-91.

Robinson, D. A. and M. G. Conzemius. 2012. The in vitro Antimicrobial Properties of Nano-magnesium Oxide (nMgO). Poster No. 1915 ORS Annual Meeting.

Robinson, D. A., R. W. Griffith, D. Shechtman, R. B. Evans and M. G. Conzemius. 2010. In vitro antibacterial properties of magnesium metal against Escherichia coli, Pseudomonas aeruginosa and Staphylococcus aureus. Acta Biomater. 6: 18691877.

Saravanan, M., A. Kumar, T. V. Padmanabhan and F. Banu. 2015. Viscoelastic properties and antimicrobial effects of soft liners with silver zeolite in complete dental prosthesis wearers: An in vivo study. Int. J. Prosthodont. 28(3): 265-269.

Singh, B., M. Bembalagi, J. M. Nagmoti, R. Patil and A. Patil. 2018. Comparison of effectiveness of silver zeolite as an antimicrobial agent in acrylic and silicone soft liners in complete denture patients: An in vivo study. Indian J. Health Sci. Biomed. Res. 11(2): 170-174.

Stencel, E. J., W. Pakieła, A. Mertas, E. Bobela, J. Kasperski and G. Chladek. 2018. Effect of silver-emitting filler on antimicrobial and mechanical properties of soft denture lining material. Materials (Basel). 11(2): 318.

The glossary of prosthodontic terms: 2017. Ninth Edition. J. Prosthet. Dent. 117(5S): 30.

Urban, V. M., T. F. Lima, M. G. Bueno, M. Giannini, J. N. Arioli Filho, A. L. de Almeida and K. H. Neppelenbroek. 2015. Effect of the addition of antimicrobial agents on Shore $\mathrm{A}$ hardness and roughness of soft lining materials. J. Prosthodont. 24: 207-214.

Valentini, F., M. S. Luz, N. Boscato and T. P. Cenci. 2017. Surface roughness changes in denture liners in denture stomatitis patients. Int. J. Prosthodont. 30: 561-564.

Wetteland, C. L., N. Y. T. Nguyen and H. Liu. 2016. Concentrationdependent behaviors of bone marrow derived mesenchymal stem cells and infectious bacteria toward magnesium oxide nanoparticles. Acta Biomater. 35: 341-356.

Yamamoto, O., J. Sawai and T. Sasamoto. 2000. Change in antibacterial characteristics with doping amount of $\mathrm{ZnO}$ in $\mathrm{MgO}$ ZnO solid solution. Int. J. Inorg. Mater. 2: 451-454.

Yamamoto, O., T. Ohira, K. Alvarez and M. Fukuda. 2010. Antibacterial characteristics of $\mathrm{CaCO}_{3}-\mathrm{MgO}$ composites. Mater. Sci. Eng. 173: 208-212.

Yanagisawa, Y. and R. Huzimura. 1981. Interaction of oxygen molecules with surface centers of UV-irradiated MgO. J. Phys. Soc. Jpn. 50: 209-216.

Zarb, G. A., C. L. Bolender, S. E. Eckert, R. F. Jacob, A. H. Fenton and R. Mericske-Stern. 2013. Prosthodontic Treatment for Edentulous Patients. $13^{\text {th }}$ ed. Mosby, St Louis.

Zayed, S. M., A. M. Alshimy and A. F. Fahmy. 2014. Effect of surface treated silicon dioxide nanoparticles on some mechanical properties of maxillofacial silicone elastomer. Int. J. Biomater. 2014: 750398. 